\title{
Chapter 14 \\ Nuclear Safety Regulation in Japan and Impacts of the Fukushima Daiichi Accident
}

\section{Hideaki Shiroyama}

\begin{abstract}
Historical progress of nuclear safety regulations and nuclear safety regulatory organizations in Japan in response to the Mutsu nuclear ship accident and JCO criticality accident are reviewed. Then the lessons we can learn from the "regulatory failures" on nuclear safety uncovered by the Fukushima Daiichi accident in 2011 are discussed focusing on the "failure" of interdisciplinary communication for setting up seismic and tsunami standards and the "failure" of voluntary safety efforts relating to the scope of sever accident management. After analyzing the policy process leading to the institutional reform after the accident aiming for independence and integrative capabilities under the newly set up organizational framework of Nuclear Regulatory Authority, remaining issues of current nuclear safety regulation in Japan, such as interdisciplinary sensitivity, capability of regulatory staff in government nuclear safety regulatory organization, independent source of expertise relating to nuclear technology in the context of Japan, and careers pattern for risk managers are also analyzed.
\end{abstract}

Keywords Safety regulation - Sever accident management - Independence • Integrative capabilities - Interdisciplinary sensitivity $\cdot$ Nuclear reactor regulation law - Nuclear Safety Commission - Nuclear and industrial safety agency • Nuclear Regulatory Authority

\subsection{Introduction}

After the Fukushima Daiichi Nuclear Power Plant accident caused by the Great East Japan Earthquake of March 11, 2011, various arguments for the reform of nuclear safety regulation were proffered. The government, in addition to setting up the Accident Investigation Committee, undertook a parallel process for regulatory

\footnotetext{
H. Shiroyama $(\bowtie)$

Graduate School of Public Policy, The University of Tokyo, 7-3-1 Hongo Bunkyo-Ku,

Tokyo 113-0033, Japan

e-mail: siroyama@j.u-tokyo.ac.jp
} 
reform. As a result, the "Basic Concept of Structural Reform of Nuclear Safety Regulations" was adopted at the Cabinet Meeting of August 15, 2011.

It advocated the launch of a new safety regulatory body, on the basis of the principle of "separating regulation from utilization." The nuclear safety regulatory divisions of the Nuclear and Industrial Safety Agency (NISA) were to be separated from the Ministry of Economy, Trade and Industry; and a "Nuclear Safety and Security Agency" would be established by April 2012 as an external agency of the Ministry of Environment by integrating into it the functions of the Nuclear Safety Commission (NSC). After the negotiation with the opposition party at the time, it was agreed to establish Nuclear Regulatory Authority as an independent commission with decision making power in June 2012, which was finally set up in September 2012.

In the history of nuclear safety regulations in Japan, major reforms were undertaken after two accidents: the Mutsu nuclear ship accident of 1974 and the JCO criticality accident of 1999. It is important to have a historical perspective to understand what will happen this time. To that end, this chapter will review the historical progress of nuclear safety regulation in Japan in response to these two accidents. This chapter then discusses the lessons we can learn from the "regulatory failures" on nuclear safety uncovered by the Fukushima Daiichi accident in 2011, and about the institutional reform and remaining issues of nuclear safety regulation in Japan.

\subsection{Historical Progress of Nuclear Safety Regulation in Japan}

\subsubsection{The First Period (1957-1978)}

We can classify as the first period the two decades from 1957, when Japan established the Law for the Regulation of Nuclear Source Material, Nuclear Fuel Material and Reactors (the Nuclear Reactors Regulation Law), to 1978, when this Law was revised.

During this period, the Prime Minister had authority to approve licenses for nuclear businesses. Actually, the Director-General of the Science and Technology Agency, who was a cabinet member, had regulatory authority through assistance to the Prime Minister. As for commercial nuclear power reactors and commercial marine reactors, however, administrative measures, including construction permits issued by the Prime Minister, required the consent of the competent ministers (Article 71 of the Nuclear Reactors Regulation Law). In this case these were the Minister of International Trade and Industry (MITI) and the Minister of Transport, because these reactors had already been regulated by the old Electricity Business Act and the Ship Safety Act. In addition, some regulatory approvals and inspections of these two types of reactors, including approvals of design and construction plan, inspections of facilities and their performance, pre-service inspections, and periodic inspections, were exempted from the application of the Nuclear Reactors Regulation Law and were left to be covered by existing regulations (Article 73). 
Meanwhile, the Nuclear Reactors Regulation Law also stipulated that the Prime Minister should listen to and respect the opinion of the Atomic Energy Commission of Japan (JAEC), which was established under the Prime Minister's Office based on Article 8 of the National Government Organization Act, including matters concerning safety regulation (Paragraph 2, Article 4). The DirectorGeneral of the Science and Technology Agency took on the position of chair person of the JAEC and this agency dealt with the staff work of the Commission. There had been controversy as to whether the JAEC should be set up as an organization prescribed in Article 3 or Article 8 of the National Government Organization Act, as the former is a decision-making organ and the latter is an advisory one. In the end, the JAEC was established as a de facto decision-making organ despite its legal nature as a very strong advisory council [1].

In this first period, one administrative agency-legally the Prime Minister, but actually the Science and Technology Agency-had nearly exclusively implemented nuclear safety regulation, even though some approvals were required by relevant ministries. Additionally, the JAEC had been established as a highly independent advisory council whose members were appointed upon confirmation from both Houses of the Diet. It was thought that the reason the JAEC had been granted a great deal of independence was so that it could ensure peaceful use of nuclear energy, as the purpose of its establishment was to provide "democratic administration of public affairs" (Article 4 of the Atomic Energy Basic Law and Article 1 of the Act for Establishment of the Atomic Energy Commission).

\subsubsection{The Second Period (1978-1999)}

The 1974 radiation leakage accident of Mutsu, the first and the only nuclearpowered ship in Japan, aroused public mistrust in the Japanese nuclear administration as a whole. The Japanese government established the Advisory Committee on Atomic Energy Administration under the Prime Minister in February 1975, whose chairman was Hiromi Arisawa, Emeritus Professor of the University of Tokyo, to reexamine the institution of nuclear-related organizations. Based on the Committee's report, the Nuclear Reactors Regulation Law was revised in 1978. We can regard as the second period the twenty years from that time to 1999 when the JCO criticality accident occurred, and the nuclear regulatory institution was reformed as a result of the reorganization of the central government.

The Arisawa Advisory Committee submitted its report in July 1976 detailing its recommendations on the reform and enhancement of nuclear administration in Japan. Three assertions closely linked with nuclear safety regulation were pointed out in this report as follows:

- To separate the functions related to nuclear safety from those of the JAEC, and to establish a new committee which shall deal with nuclear safety and doublecheck the safety reviews by the administrative agencies for enhancing the institutional framework of securing nuclear safety; 
- To implement safety regulations consistently according to the types of reactors to clarify the responsibility of administrative agencies for ensuring the safety of nuclear reactors - the Minister of MITI be responsible for the regulation of commercial nuclear power reactors, the Minister of Transport for those of commercial marine reactors, and the Prime Minister for those of research and test reactors and those in the stage of research and development; and

- To implement some government measures such as holding public hearings and symposia to dispel the public's concerns over nuclear safety and obtain the public's understanding and cooperation on nuclear energy development [2].

Based on these recommendations, the Nuclear Reactors Regulation Law was revised in 1978 as described below. First, this revision assured consistency of safety regulations with respect to each type of reactor for ensuring their safety as follows: commercial nuclear power reactors would be regulated by the Minister of MITI, commercial marine reactors by the Minister of Transport, and research and test reactors and those in the stage of research and development by the Prime Minister. Next, the functions relevant to safety were separated from the JAEC and the Nuclear Safety Commission of Japan (NSC) was newly established to exercise jurisdiction over nuclear safety issues. Still, the legal position of the NSC fell under the category of "Councils, etc." prescribed in Article 8 of the National Administrative Organization Act as did that of the JAEC. As a result of this reform, the competent ministers were required to listen to and respect the opinions of the NSC about safety-related issues when they designated activities and issued permits; and the NSC stated its opinion in the form of double-checking safety reviews of the competent ministers on nuclear regulation. Meanwhile, neither the NSC nor the JAEC had its own secretariat, so the Science and Technology Agency dealt with the staff work of both Commissions.

With regard to the institutional form of the NSC and that of the JAEC whose reform was also re-examined at that time, the controversy as to whether an Article 3 organ or an Article 8 organ was adequate was rekindled. The Arisawa Committee concluded that the NSC and the JAEC should be "advisory committees" although the Socialist Party of Japan, the Japanese Communist Party, and the Federation of Electric Power Related Industry Workers' Unions of Japan proposed changing these institutional forms to "administrative committees" which have executive authority, such as the Japan Fair Trade Commission. The Arisawa Committee provided two reasons to support its conclusion as follows:

- Under the form of administrative committee, the JAEC and the NSC could not sufficiently perform their role as "the guardian of the Atomic Energy Basic Law" and would lose their ability to monitor the government because to become administrative committees meant being part of the government.

- The primary need was to secure the autonomy of both committees from the government from the viewpoint of ensuring the peaceful use of nuclear energy which was the starting point for Japan's nuclear energy development [3].

In addition to these considerations, the problem of the scope of authority was taken into account. That is, administrative committees could not deal with any 
issues other than their own administrative affairs authorized clearly by law. That meant there was the possibility that they would not be able to cover all the safetyrelated issues unless the laws prescribed the scope of authority very broadly; and that making a broad stipulation could overlap with the authority of other governmental agencies [4].

Furthermore, two public hearings would need to be held during the siting process of nuclear power plants (NPPs). Primary public hearings were held by MITI concerning various issues related to construction of NPPs before the Electric Power Development Coordination Council (so-called "Den-Chō-Shin") decided the Electric Power Development Master Plan for building new commercial nuclear power reactors. And secondary public hearings would be held by the NSC on the occasion of double-checking safety review documents submitted by MITI [2].

In this second period, the regulatory authorities were decentralized. What is more, several governmental agencies, including the ministries which had held jurisdiction over the development and promotion of nuclear businesses, also regulated nuclear safety according to the types of business. This was because the centralized regime of safety regulation in the first period had been judged not to work adequately. However, it can be said that these changes strengthened the integration inside each type of business, which meant the level of integration between the promotion side and the regulation side was enhanced. In addition, the highly independent advisory committee became responsible for the preliminary review of regulation by the regulatory agencies.

\subsubsection{The Third Period (Since 1999)}

The JCO (a nuclear fuel production company) criticality accident of September 1999 killed two workers, the first victims in the history of nuclear energy development in Japan, and caused radiation release which forced the evacuation of nearby residents. The report of the "Investigation Committee on the Criticality Accident at Uranium Processing Plant" proposed some measures related to regulatory issues as follows:

- Strengthening and enhancement of the capacities of regulatory agencies;

- Strengthening the independence of the NSC and the capacities of the NSC secretariat and ensuring input from expert groups in a variety of fields;

- Improving regulatory guides and making the multi-layered and mutually complementary regime of safety regulation function more effectively; and

- Enhancing the regulatory agency's and the NSC's responses to demands from society and the requirements of the present age, and improving their self-inspection.

The NSC in response to this report formulated its directions for ensuring nuclear safety in the Basic Policies for the Near-Term Initiatives of the NSC (NSC Decision in November 1999) as follows:

- To devote more attention to the viewpoint of operation management in the safety review of basic designs by adding experts in this field; and 
- To verify the conditions in the operation stage as to whether the operators are maintaining their technical capabilities and taking appropriate safety measures. To assure that safety concepts are being followed at the time of the safety review, by receiving reports from the regulatory agencies on the compliance status of operational safety programs on the implementation status of periodic inspections and by conducting on-site inspections by the NSC itself.

The secretariat of the NSC was transferred from the Nuclear Safety Bureau of the Science and Technology Agency to the Prime Minister's Office in April 2000. This change brought about enhancement of human resources and improvement of the secretariat's capability to conduct expert investigations through such means as assigning experts from a wide range of areas as technical advisors, although it was a transitional institution until it was shifted to the Cabinet Office in 2001. In addition, the NSC institutionalized "the subsequent regulation review" of post-license regulations, which meant those regulations covering post-approval installation for nuclear facilities, including verification by on-site inspection for confirming the status of implementation of safety measures at construction and operation stages. The NSC published "The Basic Policies for the Near-Term Initiative of the NSC" (NSC Decision of June 2000) based on some trial implementations. Since then, the NSC began to implement fully the subsequent regulation review.

At the beginning of November 1999, there was a movement by the Administrative Reform Task Force of the Liberal Democratic Party to strengthen the NSC as an organization prescribed in Article 3 of the National Government Organization Act [5], but this was not put into action.

Furthermore, due to the reorganization of central government ministries, the regulation of commercial power reactors, reactors at the stage of research and development, and nuclear fuel facilities, etc. had come under the jurisdiction of the Minister of the Ministry of Economy, Trade and Industry (METI). However, the regulation of commercial marine reactors was placed under the jurisdiction of the Minister of Land, Infrastructure and Transportation from the Minister of Transport, and that of test and research reactors under the jurisdiction of the Minister of Education, Culture, Sports, Science and Technology (MEXT) from the Prime Minister (substantially from the Director-General of the Science and Technology Agency). In accordance with the abolishment of the Prime Minister's Office and the establishment of the Cabinet Office, the JAEC and the NSC had come under the Cabinet Office, and the NSC had come to have its independent secretariat in the Cabinet Office.

Also, organizations inside METI were restructured at that time. The Nuclear and Industrial Safety Agency (NISA) was newly established as an organization under METI-its legal position is a "Special Organ" attached to the Agency for Natural Resources and Energy. The purpose of this reform was to clarify the mission and responsibility of the agency in charge of nuclear safety administration, while ensuring independence to some extent, although it was still under METI [6].

It can be said that this government reorganization gave NSC greater independence because it was transferred to the Cabinet Office which has a higher position than the other Ministries, whereas previously it had been under the Prime Minister's 
Office which was at the same level as the other Ministries, and the NSC had come to have its own secretariat. However, the original stipulation of "respect for decisions" prescribed in Article 3 of the Act for Establishment of the Atomic Energy Commission and the Nuclear Safety Commission was deleted in the revision in 1999, although the same sentence had been transferred to Article 23 in the revision in 1978 at the beginning of the second period. It would seem that the administrative reform had got rid of the provision of respecting the decisions of advisory councils without exception.

The NSC's involvement in post-license regulations was institutionalized as "the Subsequent Regulation Reviews (SRR)" in the third period in response to the JCO criticality accident, after its embryonic stage in the second period. Since then, the SSR has been implemented and advanced in response to various incidents. On October 29, 2002, for the first time since its establishment in 1978, the NSC submitted to the Minister of METI through the Prime Minister, "Recommendations for Restoring the Confidence of Nuclear Safety" based on Article 24 of the Act for Establishment of the Atomic Energy Commission and the Nuclear Safety Commission in response to Tokyo Electric Power Company's misconduct in concealing and falsifying inspection records. In addition, the regulatory agencies were required periodically to inform the NSC of the status of implementation of subsequent regulations since the amendment of the Nuclear Reactors Regulation Law in 2002 (Paragraph 3, Article 72). Moreover, this law amendment required the nuclear operators and their maintenance and inspection subcontractors to cooperate with the NSC's inspection in response to reports from the regulatory agencies.

On March 3, 2003 the NSC established new "Subsequent Regulation Review Implementation Guidelines" reflecting a stronger monitoring and oversight function for the subsequent regulations. This guideline set the performance goal of the SSR as "to clarify the responsibility of government and operators" for prompting the regulatory bodies to develop the continuous upgrading of quality, effectiveness, and transparency of post-license regulation activities [7].

\subsection{Two Regulatory "Failures"-Systemic Causes of the Fukushima Daiichi Accident}

The Fukushima nuclear accident reveals two "failures" of nuclear safety regulation in Japan.

\subsection{1 “Failure" of Interdisciplinary Communication}

First is the "failure" of interdisciplinary communication. The Fukushima Daiichi accident has made it clear that there was a severe delay in implementing tsunami counter measures. Why, then, could Japan not succeed in applying necessary measures against tsunamis? 
In Japan, there had been a delay in taking actions to deal not only with tsunamis but also with seismic risks. However, the first decade of this century saw some progress in earthquake countermeasures. In September 2006, the Nuclear Safety Commission in Japan (NSC) revised the Regulatory Guide for Reviewing Seismic Design of Nuclear Power Reactor Facilities in accordance with the results of the 5 year study by the Subcommittee for the Regulatory Guide for Reviewing Seismic Design, which was established under the NSC in July 2001. With this revision, the Nuclear and Industrial Safety Agency (NISA) instructed nuclear operators to evaluate the seismic safety of existing nuclear facilities (so-called "back-checks") and reviewed its findings. In addition, the Chūetsu-oki Earthquake of July 2007, which shook the Kashiwazaki-Kariwa nuclear power plant with maximum seismic accelerations exceeding the levels assumed in the design, had made such efforts more imperative.

These processes, however, had not gone smoothly. In particular, there was a communication gap between the expert community on nuclear reactor safety, which consisted mainly of those in the engineering field, and that of earthquake resistance, which was made up of those in the scientific field.

As to the tsunami measures, Japan has responded in incremental ways. For example, the Tsunami Evaluation Subcommittee of the Japan Society of Civil Engineers (JSCE) published its "Tsunami Assessment Method for Nuclear Power Plants in Japan" in February 2002. The basic concept of this assessment method was to evaluate the design water level based on analysis of records of historical tsunamis and on some calculations with parameter variations. All the power companies which had nuclear power plants in Japan devised voluntary countermeasures against tsunamis based on this assessment method.

However, the Japanese nuclear community was unable to incorporate the rapid scientific progress in understanding tsunamis. For instance, in August 2002, the Earthquake Research Committee of the Headquarters for Earthquake Research Promotion, led mainly by scientific researchers, pointed out the possibility of earthquakes centered in plate boundary ocean areas which can be stronger than historical earthquakes. In addition, new simulation methods combined with sedimentological studies brought some new findings on the Jōgan earthquake of 869 mentioned in reliable historical records. Based on these findings, some tsunami experts estimated possible tsunami levels in the Fukushima coastal area higher than earlier predictions. Such advances in tsunami research have made the uncertainty of tsunami prediction more evident among the tsunami experts' community. Nevertheless, their recognition of this uncertainty was not transmitted to the nuclear safety community.

Moreover, in the Revised Regulatory Guide for Reviewing Seismic Design of Nuclear Power Reactor Facilities mentioned above, tsunamis are treated as part of the "accompanying phenomena" of earthquakes despite some subcommittee members' claim that tsunamis required particular attention in the revision process. The revised guide has only ambiguous stipulations about tsunamis as follows: "Safety functions of the Facilities shall not be significantly impaired by tsunami which could be reasonably postulated to hit in a very low probability in the service period of the Facilities." 
Having taken some measures to counter seismic risks, the nuclear safety community was placing importance on tsunami risks as well. To cite a case, the Japanese Nuclear Energy Safety Organization (JNES), one of the technical support organizations in Japan, released study results of a tsunami probabilistic safety assessment (PSA) in December 2010 just before the Fukushima Daiichi accident. This study shows that tsunami levels above a certain height cause a high incidence of reactor core melt. However, these study results were not relayed to the regulatory body, NISA.

We can see from the above that insufficient interdisciplinary communication is one of the background factors in the delay in taking actions against tsunami risks. When utilizing a complex technology system such as nuclear technology, we are required to develop awareness of trends in a broad range of fields of knowledge. Nevertheless, we would have to say that institutions in Japan lacks a refined "antenna" which can constantly detect recent findings in different expert communities. It can be said that this is one of the fundamental functions expected of the regulatory body.

\subsection{2 "Failure" of Voluntary Safety Efforts}

Second is the "failure" of voluntary safety efforts by private nuclear utilities. Nuclear safety regulation in Japan has had a tendency toward relying heavily on operators' voluntary safety efforts. The current institutional design, where NISA is located under the Ministry of Economy, Trade and Industry (METI), has been well adapted to such attributes of regulation.

Though belatedly, Japan introduced its system for severe accident management in 1992. However, under the regulatory scheme of voluntary safety efforts, accident management measures were basically regarded as voluntary efforts to be made by operators, not legal requirements. Moreover, in Japan, it was decided in keeping with the intention of operators that the PSA(Probability Safety Assessment), which provides the basis for accident management, limit its scope to internal events, and exclude external events including earthquakes. These reflected operators' concerns on gaining public acceptance in siting areas as well as technical challenges involved in evaluations of external events.

Voluntary measures for severe accident management, however, became subject to informal evaluation by the regulatory body in the periodic safety review (PSR), which is one of the quality assurance activities taken up by operators voluntarily every 10 years. Through this informal evaluation, severe accident management had gradually expanded its scope to include external events such as fires. We might say that such voluntary safety efforts were effective to a certain extent.

However, when NISA made the PSR obligatory as a requirement of operational safety regulations after some scandals involving TEPCO's cover-ups of cracks in shrouds in 2002, NISA left the PSA-related matters as voluntary requirements because of insufficient technical expertise to conduct PSAs. As a result, NISA no longer evaluated severe accident management informally, and the expansion of the scope of the PSA was halted. This can be regarded as an adverse effect of institutionalizing voluntary safety efforts. 
Operators had taken voluntary measures against tsunami risks as well. It was the electricity industry that supported a series of studies by JSCE on tsunami assessment technologies as mentioned above. Power companies also showed their concern about the new simulation studies on the Joggan tsunami, and tried to seek countermeasures by making contact with researchers on this project.

In the end, such voluntary efforts were too slow to prevent this accident caused by the earthquake and tsunami. In addition, the delay in accident responses is assumed to be due also to the circumstance that it was hard for the operator to vent voluntarily without the government's involvement. Considering these points, we must conclude that there have been some real limitations in the conventional methods of voluntary safety efforts.

This does not necessarily mean, however, that the official regulation system by the regulatory body would be completely effective. As for the responses to tsunami risks, it was not the electricity industry but the regulatory body that should have commissioned the studies on tsunami assessment technologies by JSCE. The regulatory body has given less attention to recent findings in related fields than operators have.

\subsection{Requirements for New Regulatory System}

Based on the lessons from these "failures," what lesson we can learn to reform nuclear safety regulation?

\subsubsection{Strengthening Independence}

First, many argued the necessity of strengthening the independence of the nuclear regulatory authority body. If one of the causes of this accident was the regulatory authority's attitude of leaving voluntary safety efforts up to industry, this argument stands to reason. In addition, as long as this accident and the responses to it have undermined confidence in the regulatory bodies, to secure their independence is a necessary requirement for rebuilding public confidence.

In the past, when the radiation leakage incident of the atomic-powered ship Mutsu in September 1974 increased the public's mistrust, the institutional design of the atomic energy administration was put on review. As a result, the NSC was established in 1978 and the so-called "double-check" system was institutionalized in Japan: direct regulation of nuclear operators by the government regulatory agencies (the former Ministry of International Trade and Industry, etc.), and supervision/auditing of those agencies by the NSC for ensuring highly credible nuclear safety. In January 2001, NISA was newly established under METI as a "Special Organ" attached to the Agency for Natural Resources and Energy in response to the JCO criticality accident of September 1999. With this reform, the primary regulatory agency for nuclear safety secured "some" degree of independence from the Agency for Natural Recouces and Energy, which is also charged with promoting peaceful utilization of nuclear power. 
These attempts at securing the independence of nuclear safety regulatory bodies, however, have coexisted with tendencies to depend on operators' voluntary safety efforts and to enhance collaboration and coordination with operators. These established ways had some merits, such as flexibility and regulatory cost savings. Still, in the case of crisis management of severe accidents like the Fukushima Daiichi accident, such institutions for nuclear safety regulation clearly caused delays in taking actions due to the unclear division of roles between operators and regulatory bodies.

Nuclear Regulatory Authority established as an independent commission with decision making power in 2012 at least satisfied this requirement of independence.

\subsubsection{Ensuring Integrative Capabilities}

Second, some claim that it is essential for the regulatory body to ensure integrative capabilities around nuclear safety. They state that although independence is important for the regulatory body, what is required is not only institutional independence but also integrative expertise to ensure substantive autonomy. In fact, we can say that the U.S. Nuclear Regulatory Commission (NRC) has integrative expertise which exercises jurisdiction comprehensively over nuclear safety, security, and safeguards for non-proliferation and has a staff of some 3,000. Similarly in France, L'Autorité de Sûreté Nucléaire (ASN) keeps those three areas under control in a comprehensive manner.

Of course, ensuring capabilities in nuclear safety regulation has been consistently an important issue in Japan too. Actually, after the JCO criticality accident and the reorganization of government ministries under the Hashimoto administrative reforms, NISA had been reinforced and JNES was established under NISA in 2003 with several functions transferred from some public-interest corporations. These regulatory agencies have been conducting mid-career recruitment from manufacturers in order to acquire technical expertise. Furthermore, NSC strengthened its secretariat functions after the JCO accident.

Despite these efforts, NISA, JNES and NSC have been facing the common challenge of human resource development. The mid-career staffs from manufacturers were certainly experts of parts of nuclear technology, but they could not always succeed in regulating in a comprehensive way, nor could they acquire enough skills as regulatory professionals to deal with operators.

In addition to these issues, there is also a problem with the adequacy of distribution of regulatory resources, that is, whether it is truly effective to establish two sets of regulatory bodies with the limited resources available after the series of administrative reforms: NISA and JNES primarily in charge of safety regulation; and NSC which conducts "double-checks." Moreover, the radiation dose regulation and the safeguard, the former which sets the overall goal of nuclear safety regulation and the latter which is essential for non-proliferation, are both under the Ministry of Education, Culture, Sports, Science and Technology (MEXT). This means that the authorities related to nuclear safety in its broad sense have 
Table 14.1 Dispersion of regulatory agencies/ institutions

\begin{tabular}{l|l|l|l}
\hline & Organization & Number & \\
\hline 1 & NSC & 100 & $* 2$ \\
\hline 2 & NISA & 330 & $* 3$ \\
\hline 3 & JNES & 450 & $* 2$ \\
\hline 4 & AIST & 35 & $* 1$ \\
\hline 5 & Nuclear Safety Association & 80 & $* 2$ \\
\hline 6 & MEXT Policy Bureau & 75 & $* 1$ \\
\hline 7 & MEXT R\&D Bureau—safeguard & 40 & $* 1$ \\
\hline 8 & JAEA & 200 & $* 1$ \\
\hline 9 & Nuclear Safety Tech Center & 150 & $* 3$ \\
\hline 10 & Sec of Radiation Council & 5 & $* 2$ \\
\hline 11 & Japan Radioisotope Association & 20 & $* 1$ \\
\hline 12 & National Inst of Radiological Sciences & 50 & $* 1$ \\
\hline & Nuclear Material Management Center & 165 & $* 2$ \\
\hline & Total & 1700 & \\
\hline
\end{tabular}

Note $* 1$ : Direct employee; $* 2$ : Including indirect employee/ management; *3: Unclear

been widely dispersed (refer to the Table 14.1 for the numbers in each organization). The dispersion of regulatory agencies led to the situation in which the chief Cabinet secretary had no choice but to constantly be the point person explaining the changing circumstances right after the outbreak of the Fukushima Daiichi accident even though he was not an expert in any nuclear field.

Under these circumstances, it is considered necessary to establish a consolidated regulatory authority for nuclear safety and to utilize human resources in an integrated manner for the efficient development of regulatory capabilities and for nurturing experts' careers.

Nuclear Regulatory Authority having jurisdiction over security and safeguard in addition to safety, and absorbing JNES, basically satisfied the requirement of integration.

\subsection{Future Challenges}

The requirements of institutional reform mentioned above are consistent with basically with the design idea of NRA, which was finally established in 2012 . However, there are still some doubts about whether this institutional reform can be solutions to the "failures."

First, we can point to the problem of whether the integration of regulatory bodies can develop an interdisciplinary sensitivity. It is certainly significant to integrate nuclear safety, security, and radiation regulations into a comprehensive regulatory system. In addition, this can be a prerequisite for legislating severe accident management to make radiation regulation a goal of the overall safety 
regulations and to change the legislative purpose of safety regulations from "(to ensure public safety by) preventing hazards" to "preventing radiation damage to the public." Moreover, some measures for nuclear safety and nuclear security can overlap considerably, particularly in the thermal management of spent fuels and in the distributed arrangement of emergency diesel generators. Furthermore, broad experience in various aspects of nuclear safety fields can be useful in order for regulatory officials to develop interdisciplinary communication skills.

However, as noted earlier, one of the "failures" revealed by the Fukushima Daiichi accident is the lack of awareness of seismic and tsunami risks. Those risks and volcano risks, which seem to be among the future challenges of nuclear safety, are risks dealt with under different jurisdictions. Thus, attention must be focused on how to develop awareness of issues beyond the jurisdiction of the integrated regulatory authority and how to ensure interdisciplinary communication among such segmented fields.

The second problem, as made clear by the Fukushima Daiichi accident, is the limitation of voluntary safety efforts, and whether it is truly possible for the integrated regulatory body to strengthen the capability of regulatory staff in government nuclear safety regulatory organization. That entails the need for ensuring its capabilities independent of operators.

In the case of the United States, the Navy, which has many nuclear submarines, has played an important role as an excellent source of nuclear professionals other than power companies. In fact, many nuclear experts from the Navy have been employed by the NRC and the secretariat of the Institute of Nuclear Power Operations (INPO), which is a self-regulating organization of nuclear operators. In Japan, it can be said that some research institutes under the former Science and Technology Agency, such as the former Japan Atomic Energy Research Institute (JAERI), have played a role somewhat similar to the U.S. Navy. However, these institutes have had a tendency to downsize their operations as Japanese science and technology policy places more emphasis on research studies that have high possibilities to be applied to meet societal needs.

In Japan, assuring the careers of risk managers who have an interdisciplinary orientation based on various experiences of risk management in different fields, could be the key to ensuring continuous availability of human resources with capabilities in nuclear safety regulation but with sufficient independence from operators in nuclear fields.

Open Access This chapter is distributed under the terms of the Creative Commons Attribution Noncommercial License, which permits any noncommercial use, distribution, and reproduction in any medium, provided the original author(s) and source are credited. 


\section{References}

1. Ito M (2003) Formation of Japanese model of administrative committee system: Administrative history of organization and institution. The University of Tokyo Press, Tokyo, pp 244-249 [in Japanese]

2. The Nuclear Safety Commission of Japan (1981) Annual report on nuclear safety 1981 [in Japanese]

3. Forum of Nuclear Energy Journalists (1981) Testimonies of journalists: Trajectory of nuclear energy for 25 years. Denryoku Shimpōsha, p 133 [in Japanese]

4. Arisawa $H$ (1977) Revision of the basic law and future nuclear energy administration. p 5 [in Japanese]

5. Kitayama T (2008) Reform of supervisory framework of nuclear energy. In: Mabuchi M, Kitayama T (eds) Policy process at the time of political realignment. Jigaku-sha Shuppan, p 132 [in Japanese]

6. Suzuki T, Shiroyama H, and Takei S (2006) "Independence" and social trust in safety regulation: the Case of nuclear regulatory commission and its implication. Sociotechnica, 4:166 [in Japanese]

7. The Nuclear Safety Commission of Japan (2002) White Paper on Nuclear Safety 2002 [in Japanese] 